\title{
Ensino de Matemática Através de Algoritmos Utilizando Jogos para Alunos do Ensino Fundamental II
}

\author{
Natalia do V. Gouvea ${ }^{1}$, Maria Clicia S. de Castro $^{1}$, Vera M. B. Werneck ${ }^{1}$ \\ ${ }^{1}$ Programa de Pós-Graduação em Ciências Computacionais \\ Instituto de Matemática e Estatística - Universidade do Estado do Rio de Janeiro \\ (UERJ) \\ Caixa Postal 20550-900 - Rio de Janeiro - RJ - Brasil \\ professoravalle@gmail.com, \{rcosta, vera\}@ime.uerj.br
}

\begin{abstract}
This paper presents an experiment of teaching Mathematics using algorithms and games for elementary school students. The idea is to consolidate, in an interdisciplinary way, the contents of angles, algorithms, and computer programming. The research objective is to support the proposal for an environment that helps the mathematics teacher of the Secondary School for the use of computational logic through games.
\end{abstract}

Resumo. Neste artigo é apresentado um experimento de ensino de Matemática utilizando algoritmos através de jogos, para alunos do ensino Fundamental II. A ideia é sedimentar, de uma maneira interdisciplinar, os conteúdos de ângulos, algoritmos e programação de computadores. O objetivo da pesquisa é fundamentar a proposta de um ambiente que auxilie o professor de Matemática do ensino Fundamental II para o uso da lógica computacional através de jogos.

\section{Introdução}

$\mathrm{Na}$ literatura não é comum encontrar ferramentas que auxiliem os professores a usar novas tecnologias, combinadas ao ensino de programação no nível de ensino Fundamental II. Baseado nesta perspectiva, através de uma vivência real, este trabalho definiu requisitos necessários para o desenvolvimento de um ambiente, cujo foco é apoiar o ensino de Matemática através da programação usando jogos.

Os cursos que abrangem a área da Computação têm incentivado o uso de jogos com o objetivo de tornar menor a lacuna existente entre o abstrato e a aplicação (Connolly et al. 2012).

É importante ressaltar que os alunos apresentam uma defasagem em diversas áreas do conhecimento, principalmente área da Matemática observada a partir do ingresso à universidade (Silva Filho et al. 2007). A defasagem é notada, em particular, em alunos dos cursos de Ciência da Computação em disciplinas que exigem raciocínio lógico, fundamentos de programação e conceito de algoritmos.

A utilização de recursos computacionais pode potencializar o desenvolvimento das diversas competências e possibilitar um processo de desenvolvimento que atenda o individual e o coletivo (Moratori, 2003). Assim, os jogos computacionais podem ser elementos motivadores para o ensino-aprendizagem em programação (Medeiros et al. 2014), desde que abordem temas incluídos na grade curricular dos alunos. 
O objetivo desse trabalho é apresentar um experimento de ensino de Matemática através de lógica computacional usando jogos. A priori, vários jogos de ensino de programação foram estudados para serem aplicados em aulas de Matemática do ensino Fundamental II. O tópico escolhido foi o conceito de ângulos, onde o aluno deve ter a compreensão desse conhecimento através de diversas atividades associando a ideias de giro, região, orientação e inclinação.

Este artigo está organizado da seguinte forma. A Seção 1 apresenta uma introdução breve do contexto da pesquisa. A Seção 2 apresenta o método para a escolha dos jogos utilizados nesse trabalho. A Seção 3 descreve o experimento de aplicação de jogos para ensinar Matemática através da programação utilizando os jogos baseados na Seção 2. A Seção 4 apresenta os resultados dessa experiência. Finalmente a Seção 5 discute as conclusões e os trabalhos futuros.

\section{Método Utilizado para a Escolha dos Jogos}

Uma revisão sistemática foi elaborada com base no trabalho de Kitchenham (2007). O objetivo é analisar as características necessárias para um ambiente educacional, que auxilie o ensino da lógica através de jogos. A questão de pesquisa é fundamental para orientar todo o processo de revisão, sendo definidas as seguintes questões: i) De qual maneira os ambientes computacionais devem ser utilizados nas escolas? ii) Qual público alvo está sendo focado nos trabalhos de pesquisa? iii) Quais as ferramentas estão sendo empregadas?

O estudo selecionado através desta revisão sistemática resultou num total de 24 artigos incluídos que responderam as três questões de pesquisa. Respondendo a questão um, os trabalhos propuseram oficinas que no primeiro momento despertem as curiosidades quanto à área tecnológica, para posteriormente apresentar o conceito de algoritmo. A proposta deve ser elaborada e projetada considerando as características e ferramentas onde o público alvo, no caso os alunos, estejam inseridos.

No caso desta experiência, focamos no ensino de ângulos que deve ser contextualizado com os ambientes escolhidos, de modo que faça parte das orientações curriculares estabelecidas pelo Ministério de Educação, referente ao ano de escolaridade e a série que os alunos participantes estejam inseridos.

Em relação à questão dois, foram destacadas ferramentas que podem ser utilizadas para o ensino de programação nas escolas, para alunos com idades variando de 10 a17 anos.

Para a questão três foram identificados oito ambientes (Tabela 1) que auxiliam o ensino da Matemática: Scratch, GameMaker, Lego Minstorms, LightBot, CodeMonkey, Kodu, Takkou e Tux. Com exceção do ambiente Tux, todos os jogos possibilitam a interdisciplinaridade da Matemática e a programação. Os conteúdos envolvidos nos ambientes abordam os conceitos de ângulos, considerando a direção e o posicionamento em relação a outro objeto e resoluções de problemas reais.

\section{Experimento}

Para a realização do experimento foi utilizado o método proposto por Wohlin (2012), que se baseia nas seguintes etapas: Escopo, Planejamento, Realização, Análise e Interpretação e Apresentação dos Resultados (Seção 4). 
V Congresso Brasileiro de Informática na Educação (CBIE 2016)

Anais dos Workshops do V Congresso Brasileiro de Informática na Educação (CBIE 2016)

\subsection{Escopo}

Esta etapa está relacionada à elaboração da hipótese esperada e o objetivo a ser alcançado. Neste caso, a hipótese para este experimento é verificar a possibilidade de tornar interdisciplinares as aulas de Matemática com o ensino de programação. $\mathrm{O}$ objetivo é propor um modelo de planejamento, por intermédio de dinâmicas de grupo, testes individuais e coletivos. Além de questionários que potencializem o aprendizado do conteúdo de Matemática, desenvolvendo a relação entre o abstrato e o prático, estimulando as habilidades computacionais dos alunos e familiarizando-os quanto à utilização das tecnologias.

Tabela 1. Ambientes para o ensino de Matemática e uma breve descrição.

\begin{tabular}{|l|l|}
\hline Ambiente & \multicolumn{1}{c|}{ Descrição } \\
\hline $\begin{array}{l}\text { Code } \\
\text { Monkey }\end{array}$ & $\begin{array}{l}\text { Jogo online que ensina programação em uma linguagem real, CoffeeScript. Linguagem esta } \\
\text { semelhante à JavaScript. Possui uma gama de conteúdos como: objetos, chamadas de } \\
\text { função, argumentos, loops, variáveis, arrays e definições de funções. O objetivo deste jogo } \\
\text { é orientar um personagem através de comandos simples. }\end{array}$ \\
\hline Kodu & $\begin{array}{l}\text { Possibilita a criação de jogos no computador e no XBOX. Utiliza uma linguagem simples } \\
\text { de programação visual. }\end{array}$ \\
\hline Minstorms & $\begin{array}{l}\text { Linha de brinquedo LEGO voltada para a área tecnológica. É utilizada para abordar a teoria } \\
\text { e a prática a fim de introduzir a robótica. Estimula a criatividade e a solução de problemas } \\
\text { do quotidiano por parte dos alunos. }\end{array}$ \\
\hline LightBot & $\begin{array}{l}\text { Têm versões online, IOS e Android. É possível interagir com o ambiente de forma a } \\
\text { observar que os movimentos são similares às ações do dia a dia. Aborda blocos de } \\
\text { comandos e padrões que se repetem. }\end{array}$ \\
\hline MAGU & $\begin{array}{l}\text { Ambiente que disponibiliza problemas reais, onde os alunos devem ser a parte principal da } \\
\text { resolução do problema. Está estruturado em duas partes: um contexto histórico, onde } \\
\text { apresenta personagens e situações que colaboram para o contexto do jogo; e um Conjunto } \\
\text { de Regras - que são as normas a serem seguidas para chegar à resolução de um problema. }\end{array}$ \\
\hline Scratch & $\begin{array}{l}\text { Inspirado no Logo que é uma linguagem gráfica de programação, fornecendo a criação de } \\
\text { animações simuladores, jogos e músicas. }\end{array}$ \\
\hline Takkou & Ferramenta que pode dar suporte ao aluno a desenvolver a capacidade de raciocínio lógico. \\
\hline Tux & $\begin{array}{l}\text { Software de suporte ao professor de Matemática possui perguntas e respostas para as quatro } \\
\text { operações fundamentais. }\end{array}$ \\
\hline
\end{tabular}

\subsection{Planejamento}

Iniciou-se esta etapa com uma pesquisa por locais onde pudessem ser realizadas todas as fases de experimentação. O experimento foi realizado no segundo semestre de 2015 , em uma escola privada localizada no bairro de Botafogo do município do Rio de Janeiro. Esta escola apresentou infraestrutura adequada para o experimento.

O experimento foi realizado com os alunos do $7^{\circ}$ ano do ensino Fundamental II. Os encontros aconteceram durante as aulas de Geometria ocorridas nas sextas-feiras, dentro do horário escolar pertinente a turma selecionada. A faixa etária dos alunos variou de 12 aos 14 anos, sendo a turma composta, inicialmente, por 25 alunos.

Para Pereira (2014) é necessário, nesta etapa, definir as diretrizes e características, dos participantes e dos ambientes a serem utilizados. Para isso, é importante a aplicação de um questionário para obter informações sobre o grupo pesquisado e assim estabelecer os números de encontros necessários, o nível de conhecimento sobre o assunto e as características dos jogos a serem escolhidos como ferramenta. $\mathrm{O}$ primeiro e segundo encontros foram definidos para se ter essa visão. 
O primeiro encontro foi organizado para uma apresentação prévia do que seria realizado e esperado dos alunos. Ao final, todos os presentes foram submetidos a um questionário contendo indagações sobre tipos de jogos preferidos, quais alunos possuíam acesso à internet, entre outras questões importantes para a execução de todo o processo de experimentação.

O segundo encontro foi dividido numa dinâmica em três etapas: introdução, montagem de um avião de papel e fase da avaliação. No momento da introdução a turma foi organizada em roda para um debate rápido, sendo questionado o passo a passo de como cada aluno faz desde acordar até chegar à escola. Todos os passos deveriam ser organizados e nomeados. Depois deste momento os alunos foram direcionados para listarem lugares ou situações onde não há a necessidade de ordem para serem feitos. Esperava-se que os próprios alunos desenvolvessem um conceito prévio de algoritmo.

A montagem do avião foi realizada com o auxílio de uma dinâmica de papel. Os alunos, separados em grupos, receberam uma folha A4 com instruções detalhadas para montar um avião de papel. Neste passo a passo, as etapas estão fora de ordem e cabe a cada grupo organizá-las de uma forma lógica em um algoritmo para a construção correta do avião. Depois que cada grupo realizou esta tarefa, os algoritmos foram trocados para que cada grupo utilizasse o algoritmo elaborado pelo grupo do lado.

A partir da análise do questionário e da observação feita ao longo do segundo encontro foi possível decidir quantos encontros seriam necessários e os jogos pertinentes para esse público alvo.

Os ambientes previamente selecionados foram jogos online e gratuitos disponibilizados pelo code.org (Partovi, 2013). O motivo da escolha foi por serem jogos gratuitos que permitem ao professor, através de um cadastro simples e gratuito, criar turmas com quantidades de alunos ilimitadas. A Figura 1 mostra este cadastro. Nesta opção o professor escolhe os jogos a serem utilizados na sua atividade, cadastra os alunos de acordo com a idade e ainda pode acompanhar o processo de cada aluno individualmente, ver estatísticas e gerenciar seus alunos. Se o aluno conclui o jogo o professor pode gerar o certificado de conclusão e analisar o progresso feito pelo aluno através dos dados disponibilizados pelo próprio ambiente.

A escolha dos ambientes foi baseada na análise de jogos similares aos da revisão sistemática. Os ambientes Frozen e Labirinto possuem características similares e desenvolvem as mesmas habilidades que os ambientes Lightbot e CodeMonkey entretanto possuem a ferramenta de gerenciamento de alunos.

Tanto no jogo Frozen como no Lightbot o professor tem a oportunidade de explorar movimentos similares com os do dia a dia com comandos do tipo "Vire à direita por 90 graus". Esses ambientes exploram também as estruturas de repetição e o jogo Frozen abrange não somente a linguagem de programação, mas também o ensino específico de ângulos, incluindo ângulos que não são tão óbvios visualmente como $5^{\circ}$, $30^{\circ}, 36^{\circ}, 60^{\circ}$ e $100^{\circ}$ entre outros. O jogo Labirinto utiliza uma maneira inovadora de trabalhar as funções através de blocos que são visuais e os alunos podem arrastar para organizar a sequência adequada. Neste ambiente, o aluno tem que ajudar um AngryBird a passar por um labirinto e são trabalhados os conceitos de sequência, como por exemplo o "Se", "Se não", "Repetir vezes" e "Repetir até que". 
V Congresso Brasileiro de Informática na Educação (CBIE 2016)

Anais dos Workshops do V Congresso Brasileiro de Informática na Educação (CBIE 2016)

Os jogos Frozen e Labirinto escolhidos permitem que através dos comandos utilizados pelo ambiente, os alunos possam visualizar o código relativo aos comandos escrito na linguagem de programação JavaScript.

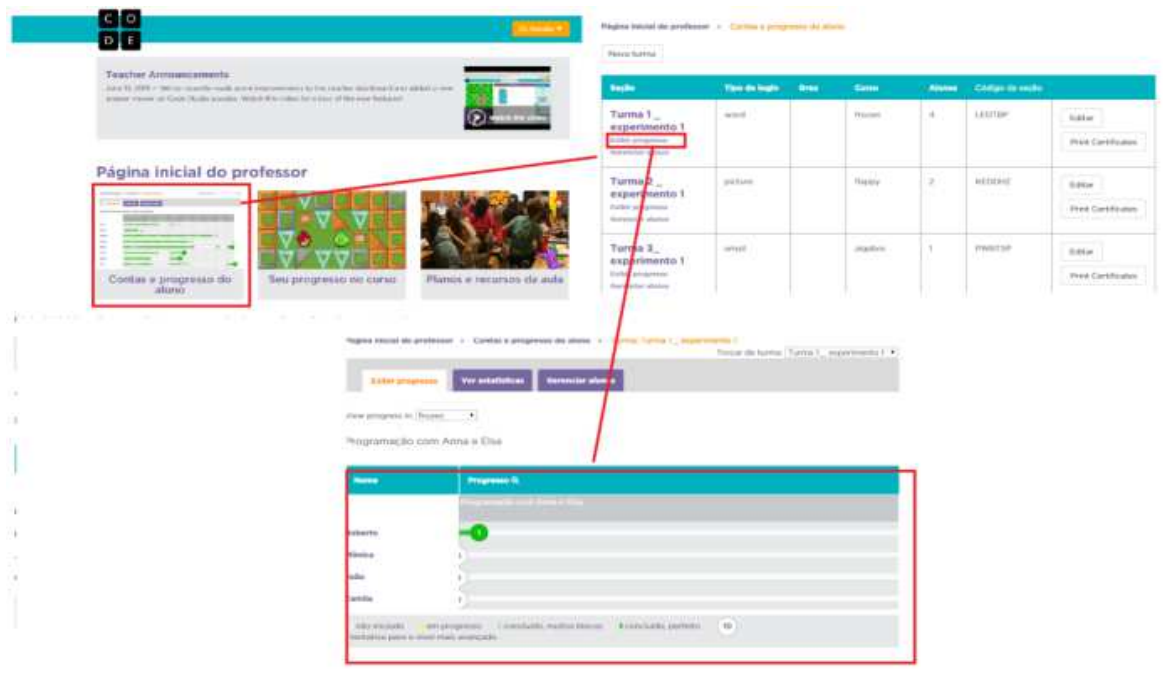

Figura 1. Cadastro de turmas do ambiente Cod.org.

Definido os jogos que seriam utilizados, foi possível traçar um plano de execução da etapa de Realização (Tabela 2).

Tabela 2. Plano do experimento para ensino de programação.

\begin{tabular}{|c|l|}
\hline Encontros & \multicolumn{1}{|c|}{ Planejamento } \\
\hline Primeiro & Aplicação de questionário avaliativo para conhecimento da realidade de cada aluno. \\
\hline Segundo & Realização de dinâmica em grupo. \\
\hline $\begin{array}{c}\text { Terceiro e } \\
\text { Quarto }\end{array}$ & $\begin{array}{l}\text { Apresentação do ambiente Code.org, suas funcionalidades, organização e possibilidades. } \\
\text { Apresentação para o aluno do ambiente Labirinto. }\end{array}$ \\
\hline Quinto & Aplicação do questionário avaliativo sobre o ambiente Labirinto. \\
\hline Sexto & Apresentação para o aluno do ambiente Frozen (realização até a fase 20). \\
\hline Sétimo & Aplicação do questionário avaliativo sobre o ambiente Frozen. \\
\hline Oitavo & Aplicação de teste escrito com questões envolvendo senso de direção sobre outro objeto. \\
\hline
\end{tabular}

\subsection{Realização}

No terceiro e sexto encontros foram apresentados os jogos Labirinto e Frozen, respectivamente. Os alunos acessaram o ambiente code.org individualmente, pois a cada aluno foi destinado um computador. Nesse momento, foram distribuídos um e-mail e uma senha para cada aluno, com a finalidade de realizar o cadastramento no ambiente. Os e-mails foram padronizados (nome+abreviatura da escola@gmail.com).

Após o momento de cadastro, os alunos começaram as suas experiências nos ambientes. As tarefas foram apresentadas pelo professor que solicitou que todas as fases fossem realizadas. A finalização das fases se deu ao longo da semana com o acompanhamento à distância pelo professor de todo o processo de concretização pelo ambiente.

O progresso foi verificado através da ferramenta de gerenciamento (Figura 2) sendo possível analisar o avanço dos alunos (numeração em branco, amarelo ou verde 
V Congresso Brasileiro de Informática na Educação (CBIE 2016)

Anais dos Workshops do V Congresso Brasileiro de Informática na Educação (CBIE 2016)

claro ou escuro). Os alunos que não iniciaram as tarefas ficam com a numeração em branco, os alunos que iniciaram e não terminaram têm a numeração em amarelo, os alunos que concluíram a fase efetivamente ficam com a numeração em verde e os que utilizaram muitos blocos de comando a numeração fica em verde mais claro.

\begin{tabular}{|c|c|c|c|}
\hline तluso & Progresso Frozed & Aluno & Progresso Labininto \\
\hline A1 & 10000000000 & $A 1$ & 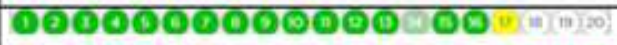 \\
\hline$A^{2}$ & 0000000000000000000 & $\overline{A^{2}}$ & 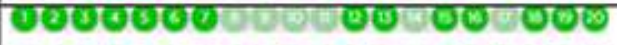 \\
\hline$A^{3}$ & 00000000000000000000 & $A^{3}$ & 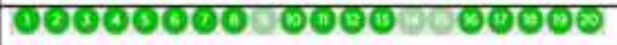 \\
\hline Ad & 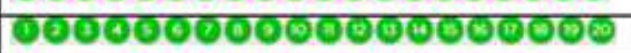 & $\overline{A 4}$ & 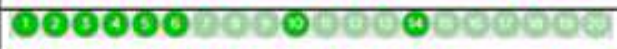 \\
\hline A5 & 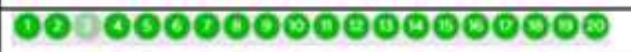 & A. 5 & 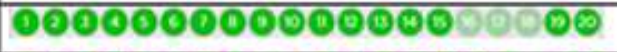 \\
\hline A6 & 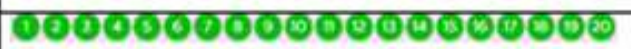 & A6 & 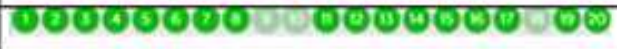 \\
\hline A? & 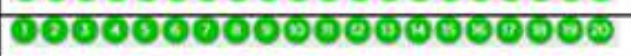 & A7 & 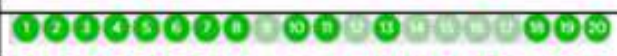 \\
\hline AS & 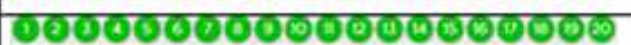 & AS & 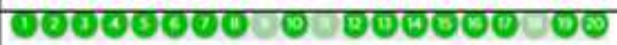 \\
\hline A9 & 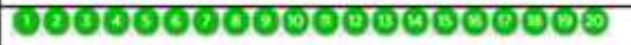 & $A^{2}$ & 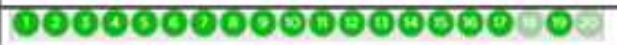 \\
\hline A10 & 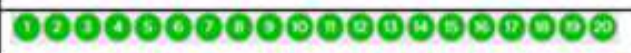 & A10 & 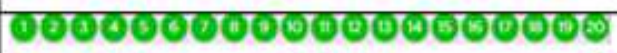 \\
\hline AII & 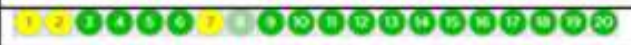 & Al1 & 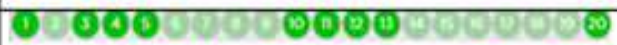 \\
\hline A12 & -000000000000000000ळ & A12 & 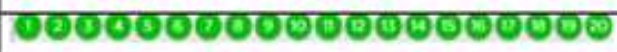 \\
\hline$A 13$ & 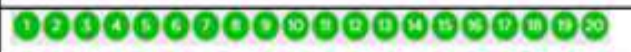 & $A 13$ & 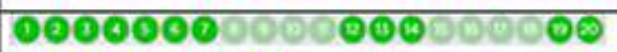 \\
\hline A14 & 0000000000000ல00000® & A14 & -000000000000 \\
\hline Al5 & 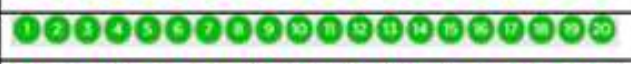 & A15 & -000000000000000000® \\
\hline A16 & $0000000000000000000 \otimes$ & A16 & ర00000000000000000৫ \\
\hline A19 & $0000000000000 \otimes 00000 \otimes$ & A17 & 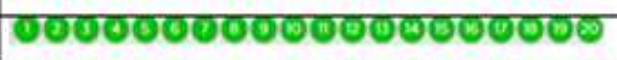 \\
\hline A18 & 000000000@000000000® & A18 & 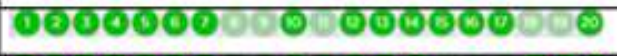 \\
\hline Aा9 & 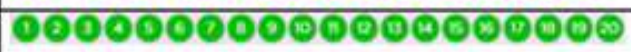 & A19 & 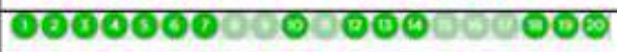 \\
\hline (220 & 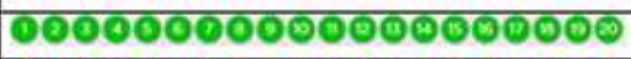 & A20 & 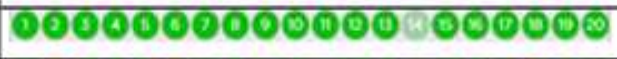 \\
\hline A21 & 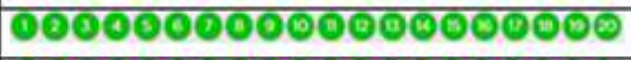 & A21 & $0000000000000000000 \otimes$ \\
\hline A22 & 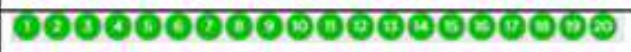 & $A 22$ & 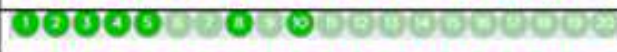 \\
\hline$\lambda 23$ & 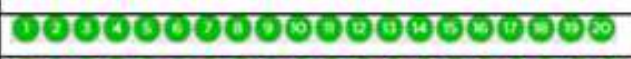 & $A 23$ & 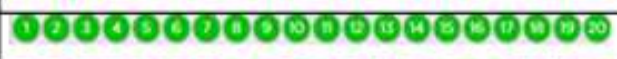 \\
\hline A24 & -00000000000000000ळ & A24 & 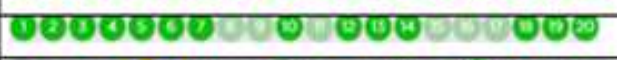 \\
\hline & 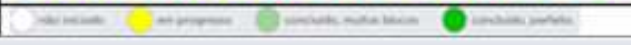 & & 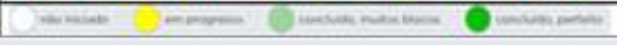 \\
\hline
\end{tabular}

Figura 2. Progresso dos alunos nos jogos Frozen e Labirinto (adaptado code.org).

No quinto e sétimo encontros foram propostos dois questionários avaliativos sobre os jogos Labirinto e Frozen, respectivamente. O questionário utilizado foi baseado no modelo de questionário MEEGA (Savi, 2011), disponível em http://www.gqs.ufsc.br/avaliacao-de-jogos-educacionais/.

O questionário original utiliza na avaliação, a escala Linkert de 5 pontos, variando entre 2 e $-2(-2 \leq x \leq 2)$. Como este questionário é para ser respondido por alunos do $7^{\circ}$ ano do ensino Fundamental II, onde nem todos ainda estão familiarizados com números negativos, decidiu-se adaptar a avaliação com variação entre 0 e 4($4 \leq x \leq 4)$.

No oitavo encontro foi elaborada uma avaliação baseada nas fases realizadas ao longo do experimento. Para Freitas (2010) as provas devem ser criadas com alternativas problematizadas e a situação estímulo favorece a organização de ideias, dados ou informações para resolver qualquer problema. Neste caso, o aluno utiliza a situação estímulo para tentar resolver as questões que são propostas a ele. 
V Congresso Brasileiro de Informática na Educação (CBIE 2016)

Anais dos Workshops do V Congresso Brasileiro de Informática na Educação (CBIE 2016)

As questões pertinentes à essa avaliação final foram elaboradas de forma unicamente discursivas, envolvendo interpretação a partir de uma situação-estímulo que compôs o enunciado.

Na fase final do experimento (oitava), obteve-se $100 \%$ de frequência e os alunos necessitaram de um tempo maior para a realização desta avaliação. Além dos 50 minutos para a sua realização, foi necessário mais aproximadamente 25 minutos. $\mathrm{O}$ nervosismo dos alunos ao tentar resolver os problemas propostos era evidente, principalmente pelo fato do tempo estar se esgotando. Desta forma cabe, através de um modo interpretativo, analisar se houve aproveitamento com o ensino de ambientes computacionais neste cenário.

\section{Análise dos Resultados}

No contexto interdisciplinar (matemático/computacional) é enriquecedor utilizar uma interpretação através da lógica Fuzzy, onde o indivíduo pode ser avaliado através do grau de pertinência. Desta forma, para estabelecer uma avaliação ainda mais questionadora o professor pode relacionar o grau de pertinência, relativo às notas, à outras métricas, como por exemplo, tempo, detalhamento da resposta, entre outros (Malvezzi, 2010).

O sistema de avaliação para o ensino Fundamental II aplicado na escola escolhida se baseia em quatro bimestres. Em cada bimestre o aluno deve somar 7 pontos envolvendo todos os trabalhos desenvolvidos. Se a média dos quatro bimestres for inferior a 4 pontos, este aluno está reprovado automaticamente. Se a média dos quatro bimestres for inferior a 7 e maior que 4, este aluno se encontra em recuperação.

As escolas de um modo geral seguem o mesmo modelo de avaliação. Analisando verifica-se que existe uma ruptura agressiva entre o aluno reprovado e o de recuperação. Assim sendo, separou-se em três conjuntos qualitativos, Insuficiente, Mediano e Satisfatório, visto na Tabela 1. No cenário escolhido, cada aluno tem um grau de pertinência em cada um destes conjuntos.

Tabela 1- Função de pertinência triangular para os conjuntos Insatisfatório, Mediano e Satisfatório

\begin{tabular}{|c|c|c|c|c|c|c|c|c|}
\hline \multicolumn{3}{|c|}{ Insatisfatório } & \multicolumn{3}{|c|}{ Mediano } & \multicolumn{3}{|c|}{ Satisfatório } \\
\hline$\pi(x)$ & $\left(\frac{5-x}{2}\right.$ & $\begin{array}{l}\text { para } 5 \leq x \\
\text { para } 3 \leq x<5 \\
\text { ara } x \leq 3\end{array}$ & $\pi(x)$ & 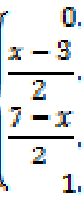 & $\begin{array}{l}\text { para } x \leq 3 \\
\text { para } 3<x \leq 5 \\
\text { para } 5 \leq x<7 \\
\text { pora } 7 \leq x\end{array}$ & $\pi(x)$ & $\frac{\frac{0}{x-5}}{2}$ & $\begin{array}{l}\text { para } 5 \leq x \\
\text { para } 5 \leq x \leq 7 \\
\text { para } 7 \leq x\end{array}$ \\
\hline
\end{tabular}

Para realizar este cálculo, foram consideradas as notas bimestrais do $3^{\circ}$ bimestre dos alunos como um dado anterior à execução das atividades. Em seguida, considerou o teste final para comparar o aprendizado referente ao novo estímulo envolvendo o ensino de programação, apresentado na Tabela 3.

Nesta etapa final de avaliação, foram considerados os graus de pertinência antes e depois do período de experimentação. A porcentagem dos alunos que possuíam o maior grau de pertinência Satisfatório era de $75 \%, 12,5 \%$ apresentaram o grau de pertinência Insuficiente e o 25\% possuíam o grau de pertinência Mediano. 
V Congresso Brasileiro de Informática na Educação (CBIE 2016)

Anais dos Workshops do V Congresso Brasileiro de Informática na Educação (CBIE 2016)

Após o experimento houve uma melhora significativa no rendimento dos alunos, considerando não somente os casos individuais citados anteriormente. A porcentagem de alunos com grau de pertinência Satisfatório subiu para 87,5\%. Além disto, houve uma redução nas porcentagens para os graus de pertinência Insuficiente $(4,16 \%)$ e Mediano $(12,5 \%)$.

Tabela 3. Avaliação dos resultados aplicando a Lógica Fuzzy.

\begin{tabular}{|c|c|c|c|c|c|c|c|c|}
\hline \multirow[t]{2}{*}{ Aluno } & \multirow{2}{*}{$\begin{array}{l}\text { Nota } \\
\text { 3ºim }^{\circ} \text { Bim }\end{array}$} & \multicolumn{3}{|c|}{ Grau de pertinência } & \multirow{2}{*}{$\begin{array}{l}\text { Nota } \\
\text { Teste }\end{array}$} & \multicolumn{3}{|c|}{ Grau de pertinência } \\
\hline & & Insuficiente & Mediano & Satisfatório & & Insuficiente & Mediano & Satisfatório \\
\hline A1 & 2,5 & 1 & 0 & 0 & 6,0 & 0 & 0,5 & 0,5 \\
\hline A2 & 6,0 & 0 & 0,5 & 0,5 & 5,0 & 0 & 1 & 0 \\
\hline A3 & $\mathbf{1 0 , 0}$ & 0 & 0 & 1 & $\mathbf{1 0 , 0}$ & 0 & 0 & 1 \\
\hline A4 & $\mathbf{8 , 5}$ & 0 & 0 & 1 & 6,5 & 0 & 0,25 & 0,75 \\
\hline A5 & 5,6 & 0 & 0,7 & 0,3 & 8,1 & 0 & 0 & 1 \\
\hline A6 & 7,5 & 0 & 0 & 1 & 6,6 & 0 & 0,2 & 0,8 \\
\hline A7 & 10,0 & 0 & 0 & 1 & 9,4 & 0 & 0 & 1 \\
\hline A8 & $\mathbf{8 , 5}$ & 0 & 0 & 1 & 6,7 & 0 & 0,15 & 0,85 \\
\hline A9 & 10,0 & 0 & 0 & 1 & 9,5 & 0 & 0 & 1 \\
\hline A10 & 7,0 & 0 & 0 & 1 & 8,3 & 0 & 0 & 1 \\
\hline A11 & 6,0 & 0 & 0,5 & 0,5 & 7,3 & 0 & 0 & 1 \\
\hline A12 & 5,5 & 0 & 0,75 & 0,25 & 6,3 & 0 & 0,35 & 0,65 \\
\hline A13 & 10,0 & 0 & 0 & 1 & 7,3 & 0 & 0 & 1 \\
\hline A14 & $\mathbf{9 , 0}$ & 0 & 0 & 1 & 7,6 & 0 & 0 & 1 \\
\hline A15 & 9,5 & 0 & 0 & 1 & 8,7 & 0 & 0 & 1 \\
\hline A16 & 8,0 & 0 & 0 & 1 & 8,1 & 0 & 0 & 1 \\
\hline A17 & 4,0 & 0,5 & 0,5 & 0 & 9,4 & 0 & 0 & 1 \\
\hline A18 & 9,5 & 0 & 0 & 1 & 7,5 & 0 & 0 & 1 \\
\hline A19 & 5,0 & 0 & 1 & 0 & 7,6 & 0 & 0 & 1 \\
\hline A20 & 9,5 & 0 & 0 & 1 & 9,0 & 0 & 0 & 1 \\
\hline A21 & 7,4 & 0 & 0 & 1 & 8,0 & 0 & 0 & 1 \\
\hline A22 & 8,5 & 0 & 0 & 1 & 5,0 & 0 & 1 & 0 \\
\hline $\mathbf{A 2 3}$ & 10,0 & 0 & 0 & 1 & 7,6 & 0 & 0 & 1 \\
\hline A24 & 3,5 & 0,75 & 0,25 & 0 & 3,7 & 0,65 & 0,35 & 0 \\
\hline Média & 7,5 & $12,5 \%$ & $25 \%$ & $75 \%$ & 7,5 & $4,16 \%$ & $12,5 \%$ & $87,5 \%$ \\
\hline
\end{tabular}

Em relação aos questionários um sumário com as médias é apresentado na Tabela 4 onde afirmações foram desenvolvidas em dez dimensões (Atenção, Relevância, Confiança, Satisfação, Imersão, Interação social, Desafio, Divertimento, Competência e Aprendizagem de curto prazo).

Algumas dimensões analisadas neste questionário podem ser comparadas com as habilidades curriculares características. Atenção, Confiança, Imersão, Interação Social, Competência e Aprendizagem são habilidades que os professores buscam em seus planos e aula. Assim como, as dimensões Relevância, Satisfação, Desafio e Divertimento são caracterizados como um feedback para o professor.

Os alunos foram avaliados sobre o seu nível de conhecimento antes e depois da utilização de cada jogo. Considerando todos os conceitos, os alunos obtiveram um aumento sobre o lembrar, compreender e aplicar. Exceto em relação ao conceito de ângulo de $90^{\circ}$, onde $32 \%$ dos alunos julgam estar no mesmo nível, antes e depois, de utilizar os jogos.

Para finalizar esta etapa de avaliação, houve um momento onde o aluno pode dissertar sobre três pontos fortes de cada jogo e sugerir três melhorias para o ambiente.

De uma maneira geral, os dois jogos tiveram fortes características positivas. Para o professor houve um bom feedback dos alunos, relativos ao cenário, níveis de dificuldade, conceitos e temas sugeridos. 
V Congresso Brasileiro de Informática na Educação (CBIE 2016)

Anais dos Workshops do V Congresso Brasileiro de Informática na Educação (CBIE 2016)

As sugestões se concentram nos graus de dificuldade de cada jogo. Deste modo, a preferência se dá para os jogos que têm uma gradação no nível de complexidade das fases. A escolha do personagem é altamente relevante para o aluno. Apesar dos cenários serem os mesmos, a maioria dos alunos escolheu um personagem diferente.

Tabela 4. Resultado dos questionários avaliativos.

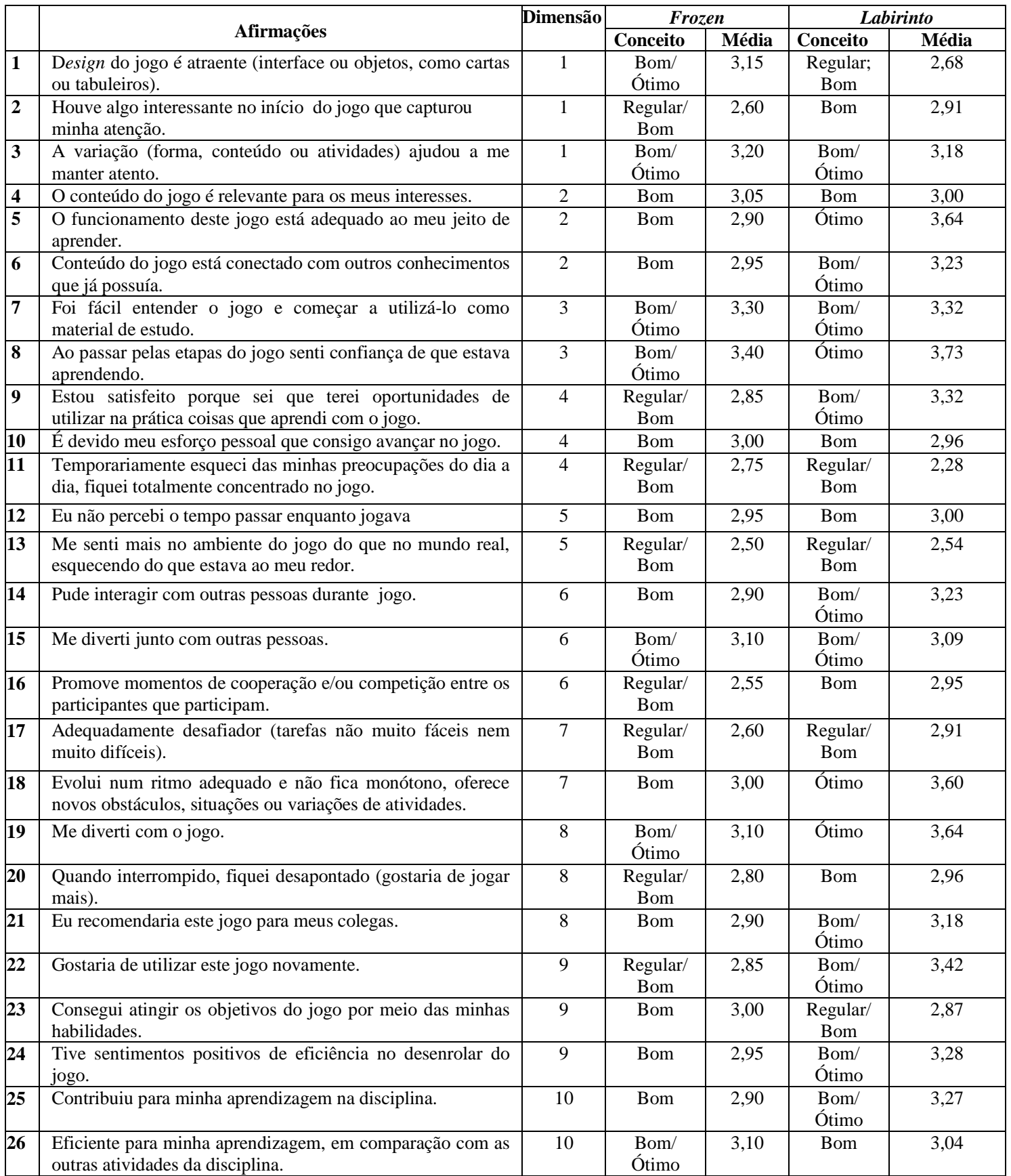

Legenda de Dimensão: 1=Atenção, 2=Relevância, 3=Confiança, 4=Satisfação, 5=Imersão, 6=Interação social, 7=Desafio, 8=Divertimento, 9=Competência e 10=Aprendizagem de curto prazo.

\section{Considerações Finais}

Neste trabalho foi apresentado um experimento utilizando jogos computacionais com objetivo de potencializar o conteúdo e minimizar a lacuna entre o ensino prático e o 
V Congresso Brasileiro de Informática na Educação (CBIE 2016)

Anais dos Workshops do V Congresso Brasileiro de Informática na Educação (CBIE 2016)

teórico da Matemática (ângulos), além de desenvolver habilidades computacionais. Para dar prosseguimento esta pesquisa, espera-se desenvolver uma proposta de um ambiente para disponibilização de conteúdos didáticos e metodologia de uso de jogos que envolvam ensino em programação, além de prover a interação entre professores do nível de ensino Fundamental II. A proposta do ambiente será feita através de levantamentos de requisitos, baseados em ambientes educacionais já disponibilizados de modo a desenvolver um ambiente que cubra as lacunas encontradas. Para os trabalhos futuros, é proposta a implementação efetiva deste ambiente no meio digital para que os professores, de fato, possam trocar suas experiências e incentivar o ensino da computação da educação básica além do uso de jogos para esse fim educacional.

\section{Referências}

Connolly, T. M., Boyle, E. A., MacArthur, E., Hainey, T., \& Boyle, J. M. (2012). A systematic literature review of empirical evidence on computer games and serious games. Computers\&Education, 59(2), 661-686.

Freitas, C.O.A. Sacalabrin, E. Martins, V. (2010). Uma proposta de Processo Contínuo de Avaliação para Cursos de Ciência da Computação. PUC-PR.

Kitchenham, B. A. (2007) Guidelines for performing Systematic Literature Reviews in Software Engineering.

Malvezzi, W. (2010). Uma ferramenta baseada em teoria Fuzzy para o acompanhamento de alunos aplicado ao modelo de educação presencial mediado por tecnologia. PUC-SP.

Medeiros, T.J., Silva, T.R. E Aranha, E. H.S. (2014) "Ensino de programação utilizando jogos digitais: uma revisão sistemática da literatura”, em:II Congresso Brasileiro de Informática na Educação (CBIE 2014)XXV Simpósio Brasileiro de Informática na Educação (SBIE 2014), Brasil.

Moratori, Patrick Barbosa. "Por que utilizar jogos educativos no processo de ensino aprendizagem." UFRJ. Rio de Janeiro (2003).

Partovi, H., Partovi, A. (2013). Code.org. Disponível em: https://code.org/.

Pereira, A. X. (2014). Diretrizes para o planejamento de experimentos em jogos educacionaisvoltados para o ensino de Engenharia de Software. UERJ/Ccomp, Rio de Janeiro.

Santos, R. P. Costa, H.A.X. (2006). Análise de Metodologias e Ambientes de Ensino para Algoritmos, Estruturas de Dados e Programação aos Iniciantes em Computação e Informática. Universidade Federal de Lavras, Departamento de Ciência da Computação. Lavras. Brasil.

Savi, R. Avaliação de Jogos Voltados para a Disseminação do Conhecimento. Florianópolis. (2011). Disponível em http://www.gqs.ufsc.br/avaliacao-de-jogoseducacionais/.

Savi, R. Avaliação de Jogos Voltados para a Disseminação do Conhecimento. Florianópolis.2011

Silva Filho, R. L. L., Motejunas, P. R., Hipólito, O.,\& Lobo, M. B. C. M. (2007). A evasão no ensino superior brasileiro. Cadernos de Pesquisa, 37(132), 641-659. 
V Congresso Brasileiro de Informática na Educação (CBIE 2016)

Anais dos Workshops do V Congresso Brasileiro de Informática na Educação (CBIE 2016)

Silva, T. S. C., de AR Tedesco, P. C., \& de Melo, J. C. (2014). A importância da motivação dos estudantes e o uso de técnicas de engajamento para apoiar a escolha de jogos no ensino de programação. In: Anais do Simpósio Brasileiro de Informática na Educação (Vol. 25, No. 1, p. 11).

Sirotheau, S., de Brito, S. R., da Silva, A. D. S., Eliasquevici, M. K.,Favero, E. L., \& Tavares, O. D. L. (2011). Aprendizagem de iniciantes em algoritmos e programação: foco nas competências de autoavaliação. In Anais do Simpósio Brasileiro de Informática na Educação (Vol. 1, No. 1).

Wohlin, C., Runeson, P., Höst, M., Ohlsson,M. C., Regnell, B., Wesslén, A. (2012). Experimentation in Software Engineering. Berlin, Heidelber. 